\title{
What's old is new again: yeast mutant screens in the era of pooled segregant analysis by genome sequencing
}

\author{
Chris Curtin and Toni Cordente \\ The Australian Wine Research Institute, Urrbrae, SA 5064, Australia. \\ * Corresponding Author: \\ Dr. Chris Curtin, E-mail: chris.curtin@awri.com.au
}

\begin{abstract}
While once de-rigueur for identification of genes involved in biological processes, screening of chemically induced mutant populations is an approach that has largely been superseded for model organisms such as Saccharomyces cerevisiae. Availability of single gene deletion/overexpression libraries and combinatorial synthetic genetic arrays provide yeast researchers more structured ways to probe genetic networks. Furthermore, in the age of inexpensive DNA sequencing, methodologies such as mapping of quantitative trait loci (QTL) by pooled segregant analysis and genomewide association enable the identification of multiple naturally occurring allelic variants that contribute to polygenic phenotypes of interest. This is, however, contingent on the capacity to screen large numbers of individuals and existence of sufficient natural phenotypic variation within the available population. The latter cannot be guaranteed and non-selectable, industrially relevant phenotypes, such as production of volatile aroma compounds, pose severe limitations on the use of modern genetic techniques due to expensive and time-consuming downstream analyses. An interesting approach to overcome these issues can be found in Den Abt et al. [1] (this issue of Microbial Cell), where a combination of repeated rounds of chemical mutagenesis and pooled segregant analysis by whole genome sequencing was applied to identify genes involved in ethyl acetate formation, demonstrating a new path for industrial yeast strain development and bringing classical mutant screens into the $21^{\text {st }}$ century.
\end{abstract}

Fermented foods and beverages, such as beer, wine, saké, and bread, owe much to the primary fermentation yeast used in their production, Saccharomyces cerevisiae. In addition to the crucial role it plays in conversion of sugars to ethanol and carbon dioxide, S. cerevisiae is responsible for an important fraction of fermented product flavour and aroma through biosynthesis of esters, higher alcohols, volatile fatty acids, and low-molecular weight sulfur compounds [2]. Biochemical pathways have been established for most compounds within these families, a particularly well-studied example being the Ehrlich higher-alcohol pathway [3]. Nevertheless, the genetic determinants of metabolic processes for production of some compounds remain elusive. One of the most significant esters produced by yeast is ethyl acetate, which imparts a "fruity", "confectionary" aroma at low concentrations, but at high concentrations is considered an off-flavour with a "solvent"-like aroma. Two alcohol acetyltransferase-encoding genes, ATF1 and ATF2, are responsible for production of the related ester, 3-methylbutyl acetate, yet when both genes are deleted approximately $50 \%$ of ethyl acetate production remains [4], highlighting the polygenic nature of this important metabolic trait.

Pooled segregant analysis is an ideal tool for the study of polygenic traits in S. cerevisiae, yet has seen only sporadic application to production of volatile aroma compounds [5-7]. Costly chemical analyses and the requirement to perform micro-fermentations of sufficient scale has undoubtedly presented a barrier for many researchers considering taking this approach, particularly because of the need for up-front large-scale screens of $S$. cerevisiae strains for production of each target metabolite [8], to identify those with significant differences. The work of Den Abt et al. [1] shows that a chemically mutagenised parent strain represents a more efficient way into the process, obviating the need for large collections of "natural" $S$. cerevisiae strains as the source of genetic variation. Indeed, in some strain collections the range of observed variation can be quite low, a case in point being extensive redundancy and genetic similarity of commercial and industryisolated wine yeasts [9]. Important to note, and a potential limitation or advantage depending upon your perspective, is that the mutant S288c variants TDA1(4) and TDA3(4) generated by Den Abt et al. [1] exhibited a large number of mutations not observed "naturally" across approximately 40 previously sequenced $S$. cerevisiae strains.

Received originally 22.03.2016, Reveised 23.03.2016, Accepted 23.03.2016, Published 31.03.2016.

Keywords: QTL, genetics, polygenic analysis, volatile aroma compound, flavour. 
In the work of Den Abt et al. [1], a relatively a large number of mutations were generated in the haploid S288c background through performing repeat rounds of chemical mutagenesis, while monitoring a range of classical phenotypes to estimate the efficacy of their treatments and ensure retention of mating proficiency. Enough mutations, though, to reveal previously unknown genetic determinants of a complex polygenic trait?

Pooled segregant analysis of a cross between mutant TDA1(4), obtained after 4 rounds of mutagenesis from a laboratory strain, and a high-producer of ethyl acetate, ER7A (haploid strain derived from a commercial strain), enabled the authors to identify three novel potential causative genes: PMA1, CEM1, and TPS1. The first two were identified as causative mutant alleles for lowering ethyl acetate production, while TPS1 is a causative genetic background allele found in S288c and not ER7A.

Likely pleiotropic effects of PMA1, which encodes a $\mathrm{H}^{+}$ATPase essential for maintenance of the plasma membrane proton gradient, make it difficult to interpret the role of this gene in ethyl acetate production. On the other hand, CEM1, a mitochondrial $\beta$-keto-acyl synthase, is a homolog of FAS2, which encodes for the $\alpha$-subunit of cytoplasmic fatty acid synthase. A gain-of-function mutation in FAS2 has previously been shown to have a profound effect on the production of medium chain fatty ethyl esters, while the concentrations of 3-methylbutyl acetate and acetic acid were reduced $[10,11]$. It has also been described that null mutations in CEM1 result in a decreased number of lipid droplets in the cell [12], and the main enzyme involved in acetate ester production during fermentation, Atf1p, is located in lipid particles. Further characterisation of CEM1 and its role in ethyl acetate production may in turn reveal novel links with production of other important flavour-active esters.

Coming back to an earlier question. Is it a limitation or advantage that the observed mutations in TDA1(4) and TDA3(4) after repeated rounds of mutagenesis were outside those found "naturally" amongst sequenced strains of S. cerevisiae? The ability to pick up both mutant and background alleles in one experiment highlights the potential power of this novel approach. Furthermore, if the goal is to identify genes that contribute to a phenotype, or to find novel alleles that confer an industrially-relevant phenotype,

\section{REFERENCES}

1. Den Abt, T. Souffriau, B. Foulquié-Moreno, M.R. Duitama, J. and Thevelein, J.M. (2016). Genomic saturation mutagenesis and polygenic analysis identify novel yeast genes affecting ethyl acetate production, a non-selectable polygenic trait. Microbial Cell 3(4): 159-175.

2. Cordente, A.G. Heinrich, A. Pretorius, I.S. and Swiegers, J.H. (2009). Isolation of sulfite reductase variants of a commercial wine yeast with significantly reduced hydrogen sulfide production. FEMS Yeast Research 9: 446-459. an efficient path to the desired endpoint is arguably more important than being able to draw conclusions about drivers of microevolution within the species. A limitation of the study is the use of a single laboratory strain genetic background to investigate a phenotype of industrial relevance in the beverage industry. The authors' state in their conclusion that small collections of independently mutagenised strains could be established, and it is important that industrial strains are amongst them so as to enable the study of industrial performance traits that laboratory yeasts do not possess. This will undoubtedly happen in the near future and by proving its utility for the study of complex polygenic traits, Den Abt et al. [1] have given the humble mutant screen a new lease on life.

\section{ACKNOWLEDGEMENTS}

The Australian Wine Research Institute is funded by Australia's grapegrowers and winemakers through their notfor-profit investment body, Wine Australia, with matching funding from the Australian Government. Omics and Systems Biology research at the AWRI uses resources provided as part of the National Collaborative Research Infrastructure Strategy (NCRIS), an initiative of the Australian Government, in addition to funds from the South Australian State Government and Bioplatforms Australia.

\section{CONFLICT OF INTEREST}

The authors declare no conflict of interest.

\section{COPYRIGHT}

(C) 2016 Curtin and Cordente. This is an open-access article released under the terms of the Creative Commons Attribution (CC BY) license, which allows the unrestricted use, distribution, and reproduction in any medium, provided the original author and source are acknowledged.

Please cite this article as: Chris Curtin and Toni Cordente (2016). What's old is new again: yeast mutant screens in the era of pooled segregant analysis by genome sequencing. Microbial Cell 3(4): 132-134. doi: 10.15698/mic2016.04.488

3. Hazelwood, L.A., Daran, J.M. van Maris, A.J.A. Pronk, J.T. and Dickinson, J.R. (2008). The Ehrlich pathway for fusel alcohol production: a century of research on Saccharomyces cerevisiae metabolism. Applied and Environmental Microbiology 74: 2259-2266.

4. Verstrepen, K.J. Van Laere, S.D.M. Vanderhaegen, B.M.P. Derdelinckx, G. Dufour, J.P. Pretorius I.S. Winderickx, J. Thevelein, J.M. and Delvaux, F.R. (2003). Expression levels of the yeast alcohol acetyltransferase genes ATF1, Lg-ATF1, and ATF2 control the formation of a broad range of volatile esters. Applied and Environmental Microbiology 69: 5228-5237. 
5. Ambroset, C. Petit, M. Brion, C. Sanchez, I. Delobel, P. Guerin, C Chiapello, H. Nicolas, P. Bigey, F. Dequin, S. and Blondin, B. (2011). Deciphering the molecular basis of wine yeast fermentation traits using a combined genetic and genomic approach. G3 1: 263-281.

6. Marullo, P. Aigle, M. Bely, M. Masneuf-Pomarede, I. Durrens, P. Dubourdieu, D. and Yvert, G. (2007). Single QTL mapping and nucleotide-level resolution of a physiologic trait in wine Saccharomyces cerevisiae strains. FEMS Yeast Research 7: 941-952.

7. Steyer, D. Ambroset, C. Brion, C. Claudel, P. Delobel, P. Sanchez, I. Erny, C. Blondin, B. Karst, F. and Legras, J.L. (2012). QTL mapping of the production of wine aroma compounds by yeast. BMC Genomics 13: 573 .

8. Steensels, J. Meersman, E. Snoek, T. Saels, V. and Verstrepen, K.J. (2014). Large-scale selection and breeding to generate industrial yeasts with superior aroma production. Applied and Environmental Microbiology 80: 6965-6975.

9. Borneman, A.R. Forgan, A.H. Kolouchova, R. Fraser, J.A. and Schmidt, S.A. (2016). Whole genome comparison reveals high levels of inbreeding and strain redundancy across the spectrum of commercial wine strains of Saccharomyces cerevisiae". G3, doi:

10.1534/g3.115.025692
10. Aritomi, K. Hirosawa, I. Hoshida, H. Shiigi, M. Nishizawa, Y. Kashiwagi, S. and Akada, R. (2004). Self-cloning yeast strains containing novel FAS2 mutations produce a higher amount of ethyl caproate in Japanese sake. Bioscience Biotechnology and Bioengineering 68: 206-214.

11. Tamura, H. Okada, H. Kume, K. Koyano, T. Goshima, T. Nakamura, R. Akao, T. Shimoi, H. Mizunuma, M. Ohya, Y. and Hirata, D. (2015). Isolation of a spontaneous cerulenin-resistant sake yeast with both high ethyl caproate producing ability and normal checkpoint integrity. Bioscience Biotechnology and Biochemistry 79: 1191-1199.

12. Ruggles, K.V. Garbarino, J. Liu, Y. Moon, J. Schneider, K. Henneberry, A. Billheimer, J. Millar, J.S. Marchadier, D. Valasek, M.A. JoblinMills, A. Gulati, S. Munkacsi, A.B. Repa, J.J. Rader, D. and Sturley, S.L. (2014). A functional, genome-wide evaluation of liposensitive yeast identifies the "ARE2 Required for Viability" (ARV1) gene product as a major component of eukaryotic fatty acid resistance. Journal of Biological Chemistry 289: 4417-4431. 